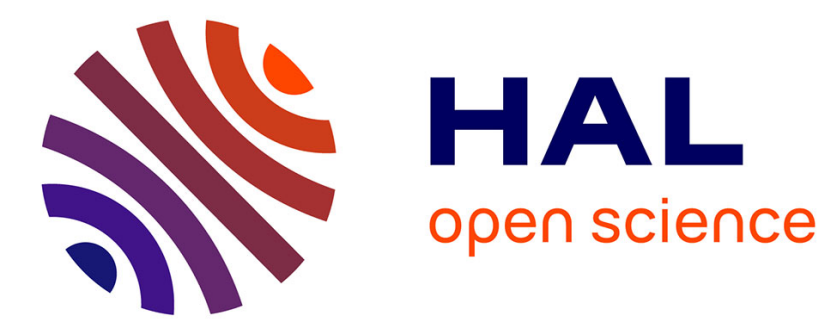

\title{
A SWOT Analysis of Virtual Reality for Seniors
}

Pooya Soltani

\section{To cite this version:}

Pooya Soltani. A SWOT Analysis of Virtual Reality for Seniors. Virtual and Augmented Reality in Mental Health Treatment, pp.78-93, 2019, 10.4018/978-1-5225-7168- . hal-01973706

\section{HAL Id: hal-01973706 https://hal.science/hal-01973706}

Submitted on 16 Jul 2019

HAL is a multi-disciplinary open access archive for the deposit and dissemination of scientific research documents, whether they are published or not. The documents may come from teaching and research institutions in France or abroad, or from public or private research centers.
L'archive ouverte pluridisciplinaire HAL, est destinée au dépôt et à la diffusion de documents scientifiques de niveau recherche, publiés ou non, émanant des établissements d'enseignement et de recherche français ou étrangers, des laboratoires publics ou privés. 


\title{
A SWOT analysis of virtual reality for seniors
}

\author{
Pooya Soltani \\ CNRS, ISM, Aix-Marseille University, France
}

\begin{abstract}
The population of older people is increasing. In this book chapter, the authors reviewed some of the applications of virtual reality (VR) for seniors in form of a SWOT (Strengths, Weaknesses, Opportunities, and Threats) analysis. This approach is commonly used to assess and guide internal and external parameters to accomplish a mission. Some of the challenges that the elderly are facing were reviewed and the way VR can help in overcoming those challenges were discussed. A comparison of VR technologies was also presented. The results show that $V R$ 's feasibility and concept are linked to existing technologies and the characteristics of each system control immersion, interaction, and stimulation. VR interventions might have the potential to be used as ecologically valid e-health screening systems. Systems should be specifically designed and adapted for seniors and usability issues should be addressed. Ideally, VR interventions work best in addition to traditional methods. Future studies should use more subjects to ensure the efficacy of such interventions for seniors.

Keywords: Elderly, Balance, Injury, Stroke, Alzheimer's Disease, Physical Activity, Technology, Rehabilitation, Fall, Stroke, Serious Game
\end{abstract}

Soltani, P. (2019). A SWOT analysis of virtual reality (VR) for seniors. In G. Guazzaroni (Ed.), Virtual and augmented reality in mental health treatment. Hershey, PA: IGI Global. doi:10.4018/978-1-5225-7168$1 . \operatorname{ch} 006$ 


\section{INTRODUCTION}

Human life expectancy and the population of elderly people over 60 years old are increasing. People might also be less available to properly support older family members. Costs of hospitalization and nursery homes, as well as physical barriers, loneliness, and isolation, are among challenges that elderly are facing (Marcelino et al., 2018). Research has shown that regular physical activity (PA) is important for good health. It could also could prevent various diseases and lower the risk of fall (Ofstedal, Zimmer, and Lin, 1999). Additionally, PA could improve memory and executive functions in the short and long term. However, aging is usually accompanied by deterioration of muscular strength, sensory sensitivity, and functional capacities (Park and Yim, 2016). These physiological changes affect the seniors' willingness to participate in regular PA (Lin et al., 2018). The physical decline also affects the elderly's quality of life, falls, admission to the healthcare centers, and mortality. Cognitive impairments also affect the elderly's functional autonomy and result in a decline in physical performance and unsafe decisions and behaviors (Dommès et al., 2015).

By means of computers interfaces, virtual reality (VR) allows users to enter a virtual world. It uses various audiovisual technologies to provide high interaction leading to a feeling of immersion (Lin, Jeng, and Yeh, 2018). VR simulates environments and activities by using real-time stimulation of one or more sensory channels. Its feasibility and concept have been linked to the existing technologies for simulation and interaction. VR settings provide immediate feedback that could be necessary for all forms of learning (Manera et al., 2016). They also offer personalized environment according to the needs of the different participants.

Although seniors shape a considerable portion of our population, they are often overlooked when it comes to newly introduced technologies. They may not always be willing to accept new technologies, in fear of not being able to use them (Lin et al., 2018). Despite the functional loss, seniors still have the abilities to acquire and re-learn performance skills (Skjæret et al., 2016). Technology might be used to promote better performance for them. Jeng, Pai, and Yeh (2017) suggested that to encourage the elderly to use technology, psychological barriers should be broken. Teaching and providing hands-on experience and assistance, increase their willingness to experience new things. VR may have the advantage to control the type and amount of experience each patient receives and may boost learning transfer to the identified targets (Maillot et al., 2017). VR also has the ability to change the existing scenarios by modifying physics and other aspects of reality. Virtual tasks might be designed according to the elderly's needs for acquiring and practicing new skills repeatedly. The immersive nature of these interventions may also offer implicit learning processes without the patient's awareness (Rand et al., 2017).

Telerehabilitation uses information and communication technology and offers accessible and affordable services to people in their homes (Kizony et al., 2017). The use of VR and serious games for older adults are generally categorized in improving upper and lower limbs movements, balance, mobility training, daily living, neglect, and cognition (cf. Deutsch and Westcott, 2017). The challenge is to provide enough amount and intensity and therefore, various technological approaches have been proposed. VR could also be used as an add-on to robotic devices for execution of movement or to be used as standalone systems using visual stimulation and interaction (Hoermann et al., 2017; Cameirão, Bermudez, and Verschure, 2008).

Considering these issues, this book chapter will present a SWOT analysis of using VR for seniors. SWOT stands for strengths, weaknesses, opportunities, and threats, and is usually used in business to analyze the parameters that affect the company's competitive position in the market. A strength is a positive capacity that allows an entity reaching to its defined goals. A weakness is a limitation that slows the progress towards the defined goals. An opportunity is an internal or external force in favor of that entity. A threat is an unfavorable situation that could present a barrier or limitation in achieving goals. SWOT analysis is done to reveal the optimal match between strengths, weaknesses, opportunities, and threats that the company is facing. SWOT framework could also be applied outside of the business domain (Rizzo and Kim, 2005). Based on a SWOT analysis, strategies could take advantage of opportunities by using their strengths and by actively addressing threats by correcting the weaknesses. 


\section{BACKGROUND}

In this part, some of the challenges that elderly people might face are explained:

Falls affect approximately one-third of older adults per year and could significantly reduce their independent functionality (Talamo et al., 2017). Injuries and fall-related costs are high and their prevention are important public health challenges. Fall risks can be attributed to both motor and cognitive deficits. Multimodal interventions that target both motor and cognitive functions may contribute to fall reduction (Mirelman et al., 2013). Surveys and physical tests are used to measure both intrinsic and extrinsic risk factors. Physical tests are easy to administer but they lack ecological validity or the degree of similarity between the training environment and the real-world. Moreover, traditional tests may not have the ability to isolate specific sensory defects (Saldana et al., 2017). This is important as ecological valid tests add value for predicting improvements in everyday functioning.

Static and dynamic balance training are usually prescribed to overcome day to day tasks in the older population. Biofeedback systems could also be beneficial for building new motor skills. They allow motor-cognitive systems integration and self-perception of treatment effectiveness (Montero-Alia et al., 2016). However, these systems are expensive, are not highly accessible, and require an expert to operate them. Other existing proactive interventions for fall preventions may also produce mixed success results because these exercises do not specifically target the neuromuscular skills required for fall prevention (Parijat et al., 2015).

Stroke is the main cause of long-term disability, and the majority of stroke patients are over 65. It creates many problems such as difficulties in completing daily living activities. Neuroplasticity and recovery after strokes are improved by repetitive, task-oriented, and intensive training. However, general barriers of cost, transport, information (on how and where to exercise), and time exist. Moreover, it seems that motivation is a major challenge for rehabilitation adherence (Paquin et al., 2016). Other parameters such as the number of exercises, their effectiveness, and their complexities might also contribute to the adherence (Pallazo et al., 2016). Stroke patients may also experience visual neglect as a result of brain dysfunction. In clinical practice, these patients are often observed for far and near space sight check.

Personally lived events are called episodic memories and they shape our identity and connect us the past and future. Changes in this type of memory (e.g. due to age) could predict the evolution towards neurodegenerative disorders (Abichou, La Corte, and Piolino, 2017). Alzheimer's disease (AD) is a common form of dementia and results in a decline in cognition and daily living activities. Mild cognitive impairment (MCI) is the limited declination of cognitive abilities in the AD. Patients with MCI have problems remembering the relationship between objects or between objects and their contexts. Spatial disorientation is another early manifestation of $\mathrm{AD}$ and $\mathrm{MCI}$ in which patients have problems in unfamiliar places.

Cognitive and functional tools are usually used to detect early manifestation of the disease. Assessing instrumental activities of daily living (e.g. using a bus or a telephone) is important for choosing better interventions for AD patients. Traditional neuropsychological tools use simple situations and are able to partially measure the characteristics of episodic memory. Ecological tasks might be more beneficial compared to subjective questionnaire-based assessments (Vallejo et al., 2017). Novel screening test uses new technology and game principles and focuses on the immersion of the users in various scenarios to mislead and deceive patients' minds (Fernandez and Argyriou, 2017). Assessing patients with VR application seems legitimate because they could recreate conditions similar to that of the real world. In the next section, the differences between different forms of VR are discussed and after, a SWOT analysis of how VR could address the mentioned challenges is presented.

\section{MAIN FOCUS OF THE CHAPTER \\ Differences between exergames and the VR}

Early studies have characterized active video games (exergames) as forms of VR. In fact, these two terms are usually used interchangeably. We have heard research findings like these: Elderly may have higher interests in participation in exergame sport activities than real-world activities (Wollersheim et al., 2010); 
When exergames are used for rehabilitation, elderly are more motivated and rarely drop out (Pigford and Andrews, 2010). There are also demented pieces of evidence on better control over posture stability and balance when using exergames (Chiang et al., 2011). So what are the differences between exergames and VR?

For a system to create the illusion of interacting with a virtual world, it should offer presence, immersion, and flow. The presence or the realness of the world is partly created by the system's ability to deliver an illusion or degree of immersion. This is where the differences of exergames and other types of hardware is more visible. Exergame platforms detect your movements with their sensors and transfer them to computerized avatars inside the games. Nintendo Wii also comes with a balance board, a small portable force platform that could be coupled with various Wii Fit games. It adds enhanced immersion by monitoring center of gravity while the participants interact with the on-screen characters (Rendon et al., 2012). More immersive virtual environments include cave automatic virtual environments (CAVE) which are basically a video theater within a room. The walls of the cave are made up of rear-projection screens. Users enter the cave while wearing 3D glasses and their movements are monitored to continuously adjust viewers' perspective. Newer technologies such as head-mounted displays (HMD) use participant-centric perspective. They have a larger field of view (FOV) and stereoscopic visual fields that are constantly modified by head position and rotation. The recent HMDs have higher FOV, display resolution, tracking latency resulting in a better creation of the visual illusion of real objects and scenarios.

One reason might be that exergame platforms provide immediate feedback to players' movements, offering immersive feelings. Therefore, VR's feasibility and concept are linked to the existing technologies for immersion, interaction, and stimulation. The characteristics of each concept control immersion (responsible for delivering an illusion of reality), which later affects presence (sense of being in the VR; Borrego et al., 2018). For example, one might argue that HMDs and CAVEs are more immersive than exergames because they provide higher visual stimulation. However, this degree of immersion is not necessarily related to the effectiveness of the system (Deutsch and Westcott, 2017), and both VR and video games create a state of flow, the optimal performance zone of the players.

Lee, Chen, and Chang (2016) argued that tasks presented on LCD displays are in fact presented in $2 \mathrm{D}$. In a $2 \mathrm{D}$ virtual environment, there is no stereo vision and subjects see one planar view and other cognitive and sensory cues may indicate depth (e.g. an avatar walking in a jungle). As patients need to imagine 3D patterns shown on the 2D display, a huge cognitive load is created when the information is presented in a 2D format (Sweller et al., 1998). They suggested that augmented reality (AR) provides better 3D stimuli and manual spatial manipulation. On the other hand, they indicated that by using AR, users might change their behavior when they are aware of being observed. Liebermann et al. (2012) also compared arm reaching movements made in 2D video VR environment with the real-world environment. They showed that movements patterns were affected by viewing angle and were slower, shorter, and less accurate compared to the real condition. They also suggested that a 2D VR environment may be perceptually and cognitively challenging for the participants because the intended 3D illusion presented by their VR was likely based on previous memories and experiences. They concluded that caution needs to be taken when using these environments for improving the quality of movement for rehabilitation of upper limb.

Another issue to consider is that visual systems contribute to balance and visual perturbation cause instability. Exergames do not completely encompass the viewer's FOV, and visual information from surroundings of the VR environment (e.g. TV or screen) can still provide stability cues (Menzies et al., 2016). HMDs obscure unwanted additional visual cues and add ecological validity through the addition of depth perception and removing external visual cues (Saldana et al., 2017). However, it may cause simulator sickness and if not properly designed or performed without supervision, may lead to falls.

\section{Strength}

Riva et al. (2004) used a VR-based multidimensional approach to treat body image (perception of the aesthetics or sexual attractiveness of one's body) attitudes. Their results showed positive short-term results in improving the overall psychological state of the participants compared to the traditional 
cognitive-behavioral training. Chang et al. (2014) compared the effects of a VR gaming system on sleep quality of elderly people with a disability. They showed that regular VR exercise significantly reduces stress among the older patients, confirming that it can improve their sleep quality. In his meta-analysis, Cardinale (2018) suggested that VR balance training using Nintendo Wii improves Borg balance scale score compared to no balance training, and helps people to multi-task during balance training. Parijat et al. (2015) used VR as a perturbation-based training tool for older adults. They found that their VR environment could induce perturbations similar to a slip. It could also reduce the incidence of balance loss during the actual experiment on a slippery surface. Mirelman et al. (2016) targeted the interplay between cognitive and mobility deficits and combined non-immersive VR gaming with treadmill training. After 6 months of training, those who trained on the treadmill using VR had a significantly lower fall incident rate compared to the treadmill only group.

Yasuda et al. (2017) examined the immediate effects of an immersive VR rehabilitation program (a reaching task and a visual searching task) using HMD on near and far spatial neglect. They concluded that this program might be beneficial for the visual searching task in far spatial neglect. Self-training compliance using video games for post-stroke rehabilitation is shown to be higher compared to traditional methods in elderly patients (Rand et al., 2017). Parsons and Barnett (2017) developed a VR measure of memory and validated it with traditional methods in older adults. Not only the VR measure was similar to traditional methods for memory measures, it provided objective measurements of individual memory components. Their subjects also preferred the VR task over the pen-and-paper measures. Vallejo et al. (2017) developed a VR serious game to assess cognitive function in healthy and AD patients using an ecological approach of daily living activities. Differences were expected between healthy and AD patients in terms of percentage of achievements and the time needed to achieve those tasks. However, the additional qualitative information regarding the errors in the achievement of the tasks provided information about cognitive functions.

Nir-Hadad et al. (2017) also validate their VR shopping task for the assessment of executive function in stroke elderly population. Maillot et al. (2017) developed an affordable and transportable VR system to help older pedestrians make safer street crossing decisions. They also measured whether training with the small-scale simulator transfers to a full-size simulator where they could actually walk. They showed that the small scale simulator triggers more unsafe decisions compared to full-scale. It also allowed learning new skills and modify behavior to use in the large-scale simulator (learning transfer).

\section{Weakness}

Manera et al. (2016) argued that their VR task needs to be improved to fix usability issues. They attributed the lower performance of elderly in VR to the difficulties elderly have with using the mouse and possibly to eye strain from wearing the 3D glasses. In general, the senior population suffers from technological illiteracy. For maximum efficacy, VR systems should promote a user-centered design and their primary focus should be on inclusive design, usability, and accessibility. Different sensors might demand higher body performances. For example, to use Kinect, it is necessary to move the whole body. Some sensors might require players to have better coordination and in elderly it might cause lower levels of performance. Other technologies like touch screens may not require high levels of body movement but may demand higher mental agility (Palacio et al., 2017).

Bezerra et al. (2018) showed that VR environments provide improvements of performance in healthy older adults. However, there is no transfer of performance from VR to the real task and vice versa. Rand et al. (2017) compared video game and traditional self-training for upper limb rehabilitation in older adults after a stroke. Although improvements were observed in the two methods, they showed that the differences were not significant. Zygouris et al. (2015) used a virtual supermarket task for MCI screening. Although the task displayed a high correct classification rate between MCI and healthy elderly, it was unable to differentiate between MCI subtypes. Dommes et al. (2012) assessed the effectiveness of a VR training program for elderly on the street crossing decision making. Although they showed that immediately after the training, the intervention group and the control group differed significantly, these differences were not significant after 6 months. However, a clear shift to making more safe decisions was 
observed for all participants. In general, due to the lower number of subjects in different studies, the generalization of the results are somewhat restricted (Yeşilyaprak et al., 2016).

\section{Opportunities}

Mattan et al. (2017) discussed that age is associated with reduced perspective-taking capacity. They showed that compared to younger adults, older people are relatively more egocentric and more accurate when they are in the first person perspective compared to the third person perspective. Mohammadi et al. (2018) also used two VR navigation tasks (allocentric and egocentric virtual neighborhoods) in different $\mathrm{AD}$ patients. They showed that patients needed more time to find the goal in egocentric tasks. It might be possible to properly distinguish specific types of AD patients from others. Sobral Monteiro-Junior et al. (2017) showed that exergaming could offer improvements in short-term memory, working memory, and semantic memory/executive function over time. Valladares-Rodriguez et al. (2017) used a digital game to assess episodic memory, which is used to evaluate potential cognitive impairments in the elderly. Using the new ecological, non-intrusive, and better administrable tool, they conducted the test in a shorter time. They could also introduce scenarios that are closer to real life while being more engaging and highly acceptable compared to the classical pen-and-paper based method.

Fernandes and Argyriou (2017) used VR as an affordable approach for creating e-health screening AD diagnostic systems. They proposed VR tests that could evaluate memory loss related to common objects, recent events, expressing and understanding languages, and the ability to recognize abnormalities accurately and similarly for the presence of AD. From their research, Plancher et al. (2012) concluded that VR is better adapted for early diagnosis of AD compared to traditional verbal memory tools. Manera et al. (2016) tested the feasibility of an image-based VR system in MCI and dementia. Their patients reported high feelings of security and low discomfort, anxiety, and fatigue. Although the VR task was more difficult, they were also more satisfied with the VR condition and preferred it to the paper condition.

Lin et al. (2018) used means-end chain techniques to examine elderly's awareness and personal values regarding VR activities. Elderly population mentioned leisure VR activities to be fun, safe, easy, and physically and mentally healthy. While playing with VR, they were also seeking enjoyment, improved quality of life, and a sense of belonging. Goršič et al. (2017) explored the role of competition while using VR. They concluded that stroke patients (including elderly) who exercise with a peer in an unsupervised situation (e.g. home) exhibit higher enjoyment and exercise intensity compared to those who exercise alone. Brunner et al. (2017) explored the effectiveness of their upper extremity VR rehabilitation system and showed that the improvements were similar to the conventional therapy. They also suggested that the motivating nature of VR could be a supplement to standard rehabilitation.

Saldana et al. (2017) used HMD in VR to objectively assess balance by using visual-vestibular conflict and by comparing the results of postural sway with a force plate. Their preliminary results showed that the HMD is a valid, reliable, and comparable to traditional mechanical perturbation approaches for measuring balance. Popular HMDs allow easy navigation in life-size virtual environments and provide required spatial requirements of non-immersive serious games, exergames, and motor rehabilitation applications (Borrego et al., 2018). Such interaction allows natural navigation and exploration and therefore, the improved ecological validity of the task while facilitating skill transfer. Albiol-Pérez et al. (2017) designed a low-cost active balance rehabilitation system and measured the performance of balance control during 15 sessions of virtual rehabilitation. Although there were no statistically significant differences between the left, central, and right positions, their results indicated a trend of improvement, especially in the left and right sway which are important in avoiding risks of falls. Tsang and $\mathrm{Fu}$ (2016) compared the efficacy of their VR balance system with traditional balance training. They attributed the improvements in VR system to the real-time performance feedback and cuing stimuli that supports error-free learning.

Paquin et al. (2016) used a VR rehabilitation program for fine motor recovery of stroke patients. All of their subjects experienced a perceived increase in hand function and that they would recommend the program to other stroke survivors. McDonald et al. (2013) used a VR pain coach for the effects on the 
communication of pain by older adults. They measured pain and depressive symptoms before and one month after the intervention. Older adults shared a significant amount of clinically important pain information with the pain coach than the pain communication-only group. Pain intensity and depressive symptoms reduction showed a non-significant trend one month after the intervention. The VR pain coach shows a possible strategy for pain management discussions between practitioners and older adults.

\section{Threats}

Previous research has suggested side effects of display characteristics, obstacles, cost/benefit of the technology as weaknesses for the adoption of VR in rehabilitation (Rizo and Kim, 2005). Dizziness and imbalance might occur after using VR applications. Chairovano et al. (2018) perturbed visual inputs and measured their effects on self-report (complaint) vs. balance measurement (posturography). As they found no correlation between these two methods, it is important not to only rely on subjective measurement of dizziness, but also to objectively measure the imbalance; especially because questionnaires could be influenced by age, sex, motivation, and cognitive and emotional parameters (Yardley and Redfern, 2001). Eggenberger et al. (2015) also compared long-term multi-component cognitive-physical tasks: one was treadmill walking with simultaneous verbal memory training and the other VR video game dancing. Both types of training resulted in significant advantages in improving gait parameters compared to physical training only. However, these two interventions resulted in different training-specific adaptations in the gait. Cardinale (2018) suggests that VR balance training should be used in supplement with other interventions. With multi-component processes such as balance, there might be the possibility of errors leading to falls. The lower number of patients, especially in different types of AD might limit the generalization of the results (Mohammadi et al., 2018).

\section{SOLUTIONS AND RECOMMENDATIONS}

Technology is constantly evolving, and it has the potential to be applied to various domains. However, it needs to be adapted to meet the seniors' needs. Lee et al. (2016) designed a VR based rehabilitation and explored patients' perceived difficulty and enjoyment. They suggested that the level of enjoyment could be an indicator of the appropriateness of the difficulty levels. They identified five parameters that could affect this relationship: ease of following the directions, the experience of pain, achieved scores, novelty and immediate feedback, and self-perceived effectiveness. Participants' physical, cognitive, proprioceptive differences should also be considered while tailoring the VR systems. As mentioned by Lin et al. (2018), elderly people's decision-making processes are restricted to certain leisure activities. Different platforms should identify their feature and consider elderly's physiological functions to establish a marketing focus.

From their systematic review, Molina et al. (2014) concluded that most of the studies on the efficacy of inclusion of exergames for elderly have methodological problems. The duration of gameplay varies widely and therefore, it is hard to be conclusive about the physical benefits. Miller et al. (2014) also mentioned that although VR/gaming systems are effective and feasible, there is a high risk of bias for addressing impairments and participation. Booth et al. (2014) also systematically reviewed 251 articles on the effects of VR gaming systems on improving balance in older adults. The pooled results showed no significant differences. What is important is that video games for older people could help them to be more socially active. However, several parameters such as simplicity, social enjoyability, and entertaining new games should be considered. Video game controller should allow adequate time for the elderly to make decisions in order to achieve the games' objectives (Palacio et al., 2017).

\section{FUTURE RESEARCH DIRECTIONS}

As mentioned before, most of the studies lack an adequate number of participants which makes it hard to generalize the efficacy of results. Future studies should use a larger sample size and consider culture and gender-oriented tasks (Vallejo et al., 2017; Yeşilyaprak et al., 2016). Future studies should also have appropriate dosages of use to improve the validity of treatment prescription and safe functioning levels of 
the seniors (Cardinale, 2018). Follow-up and longitudinal studies with normalized baseline levels are required to identify the consistency of the beneficial effects of VR (Maillot et al., 2017; Nawaz et al., 2016; Mirelman et al., 2016). Feasibility studies are important in enhancing performance and other cognitive tasks in the target population. However, RCT efficacy studies should be conducted with control groups of healthy elderly participants, while creating more complex versions of the task (Kizony et al., 2017; Marena et al., 2016). Control groups and blinding participants and the tests also help in avoiding bias and learning effects (Yasuda et al., 2017). Similar VR and real tasks could also help in better understanding the transferability of the intervention (Bezerra et al., 2018). It is also important to assess psychosocial and cognitive emotion improvements after VR interventions (Cardinale, 2018). As suggested before, it is also important to consider the VR training as part of a holistic platform and not the sole effects (Cardinale, 2018).

\section{CONCLUSION}

VR is a rapidly developing subject and in this book chapter, the authors discussed how VR could help in overcoming various struggles of the seniors. Both exergames and newer VR technologies have the ability to immerse players and their effectiveness may not be related to the levels of immersion they offer. However, each technology might address specific needs. As shown in Table 1, it seems that VR interventions have the potential to offer ecologically valid scenarios for screening various diseases. It is suggested that these interventions are used in addition to traditional interventions. More subjects and longer duration of use are needed to validate the efficacy of VR for seniors.

Table 1. Summary of SWOT analysis of using VR for seniors

\begin{tabular}{|l|l|}
\hline Strengths & Weaknesses \\
1- Short term overall psychosocial state improvements & 1- Adaptation issues (usability, display technologies, \\
2- Improved balance and decreased risks of falls & platforms) \\
3- Improved visual searching & 3- Limitations in skill transfer \\
4- Higher compliance to self-training & cognitive tests \\
5- Similar validity to traditional memory tests & 4- Short lasting results \\
6- Enhanced ecological validity & 5- Restricted generalization of the results \\
\hline $\begin{array}{l}\text { Opportunities } \\
\text { 1- Ability to modify physics and scenarios according to }\end{array}$ & $\begin{array}{l}\text { Threats } \\
\text { 1- Mixed positive and negative results }\end{array}$ \\
2- Efficiency & 2- Low number of subjects \\
3- Affordable & 3- Little cost/benefit proofs for VR adoption \\
4- Possible similar results to traditional interventions & \\
\hline
\end{tabular}




\section{REFERENCES}

Abichou, K., La Corte, V., \& Piolino, P. (2017). Does virtual reality have a future for the study of episodic memory in aging? Geriatrie et Psychologie Neuropsychiatrie du Vieillissement, 15(1), 65-74. doi:10.1684/pnv.2016.0648

Albiol-Pérez, S., Gil-Gómez, J. A., Muñoz-Tomás, M. T., Gil-Gómez, H., Vial-Escolano, R., \& Lozano-Quilis, J.-A. (2017). The effect of balance training on postural control in patients with Parkinson's disease using a virtual rehabilitation system. Methods of Information in Medicine, 56(2), 138-144. doi:10.3414/ME16-02-0004

Booth, V., Masud, T., Connell, L., \& Bath-Hextall, F. (2014). The effectiveness of virtual reality interventions in improving balance in adults with impaired balance compared with standard or no treatment: A systematic review and meta-analysis. Clinical Rehabilitation, 28(5), 419-431. doi:10.1177/0269215513509389

Bezerra, I. M. P., Crocetta, T. B., Massetti, T., Silva, T. D. D., Guarnieri, R., Meira, C. d. M., Jr., . .. Monteiro, C. B. d. M. (2018). Functional performance comparison between real and virtual tasks in older adults: A cross-sectional study. Medicine, 97(4), e9612-e9612. doi:10.1097/MD.0000000000009612

Borrego, A., Latorre, J., Alcaniz, M., \& Llorens, R. (2018). Comparison of Oculus Rift and HTC Vive: Feasibility for Virtual Reality-Based Exploration, Navigation, Exergaming, and Rehabilitation. Games for health journal.

Brunner, I., Skouen, J. S., Hofstad, H., Aßmus, J., Becker, F., Sanders, A. M., . . Verheyden, G. (2017). Virtual reality training for upper extremity in subacute stroke (VIRTUES): A multicenter RCT. Neurology, 89(24), 2413-2421. doi:10.1212/WNL.0000000000004744

Cameirão, M. S., Bermúdez, S., \& Verschure, P. F. M. J. (2008). Virtual reality based upper extremity rehabilitation following stroke: A review. Journal of CyberTherapy \& Rehabilitation, 1(1), 6374.

Cardinale, J. (2018). Does Virtual Reality Balance Training Utilizing the Wii Balance Board Improve Balance in Community Dwelling Older Adults: A Meta-Analysis (Doctoral dissertation, California State University, Fresno).

Chang, L. C., Wang, C. Y., \& Yu, P. (2014). Virtual reality improves sleep quality amongst older adults with disabilities. International Journal of Geriatric Psychiatry, 29(12), 1312-1313. doi:10.1002/gps.4172

Chiang, I. T., Chen, M. L., Chang, P. S., \& Lee, J. Y. (2011). Effects of a video game-based intervention on balance learning for institution-dwelling elderly in veterans home. In The 2011 International Educational Technology Conference Proceedings Book (Vol. 1, pp. 393-398).

Chiarovano, E., Wang, W., Reynolds, P., \& MacDougall, H. G. (2018). Imbalance: Objective measures versus subjective self-report in clinical practice. Gait \& Posture, 59, 217-221. doi:10.1016/j.gaitpost.2017.10.019

Deutsch, J. E., \& Westcott McCoy, S. (2017). Virtual reality and serious games in neurorehabilitation of children and adults: Prevention, plasticity, and participation. Pediatric Physical Therapy: The Official Publication of The Section on Pediatrics of the American Physical Therapy Association, 29 Suppl 3, S23-S36. doi:10.1097/PEP.0000000000000387

Dommès, A., Le Lay, T., Vienne, F., Dang, N. T., Beaudoin, A. P., \& Do, M. C. (2015). Towards an explanation of age-related difficulties in crossing a two-way street. Accident Analysis \& Prevention, 85, 229-238. doi:10.1016/j.aap.2015.09.022

Dommes, A., \& Cavallo, V. (2012). Can simulator-based training improve street-crossing safety for elderly pedestrians? Transportation Research Part F: Psychology and Behaviour, 15(2), 206-218. doi:10.1016/j.trf.2011.12.004

Eggenberger, P., Theill, N., Holenstein, S., Schumacher, V., \& de Bruin, E. D. (2015). Multicomponent physical exercise with simultaneous cognitive training to enhance dual-task walking of older adults: A secondary analysis of a 6-month randomized controlled trial with 1-year follow-up. Clinical Interventions in Aging, 10, 1711-1732. doi:10.2147/CIA.S91997 
Fernandez Montenegro, J. M., \& Argyriou, V. (2017). Cognitive evaluation for the diagnosis of Alzheimer's disease based on Turing Test and Virtual Environments. Physiology \& Behavior, 173, 42-51. doi:10.1016/j.physbeh.2017.01.034

Goršič, M., Cikajlo, I., Goljar, N., \& Novak, D. (2017). A multisession evaluation of an adaptive competitive arm rehabilitation game. Journal of Neuroengineering and Rehabilitation, 14(1), 128-128. doi:10.1186/s12984-017-0336-9

Hoermann, S., Ferreira Dos Santos, L., Morkisch, N., Jettkowski, K., Sillis, M., Devan, H., . . . Cutfield, N. J. (2017). Computerised mirror therapy with Augmented Reflection Technology for early stroke rehabilitation: Clinical feasibility and integration as an adjunct therapy. Disability and Rehabilitation, 39(15), 1503-1514. doi:10.1080/09638288.2017.1291765

Jeng, M.-Y., Pai, F.-Y., \& Yeh, T.-M. (2017). The virtual reality leisure activities experience on elderly people. Applied Research in Quality of Life, 12(1), 49-65. doi:10.1007/s11482-016-9452-0

Kizony, R., Weiss, P. L., Harel, S., Feldman, Y., Obuhov, A., Zeilig, G., \& Shani, M. (2017). Telerehabilitation service delivery journey from prototype to robust in-home use. Disability and Rehabilitation, 39(15), 1532-1540. doi:10.1080/09638288.2016.1250827

Lee, I. J., Chen, C. H., \& Chang, K. P. (2016). Augmented reality technology combined with threedimensional holography to train the mental rotation ability of older adults. Computers in Human Behavior, 65, 488-500. doi:10.1016/j.chb.2016.09.014

Lee, M., Pyun, S. B., Chung, J., Kim, J., Eun, S. D., \& Yoon, B. (2016). A further step to develop patient-friendly implementation strategies for virtual reality-based rehabilitation in patients with acute stroke. Physical Therapy, 96(10), 1554-1564. doi:10.2522/ptj.20150271

Liebermann, D. G., Berman, S., Weiss, P. L. T., \& Levin, M. F. (2012). Kinematics of reaching movements in a 2-D virtual environment in adults with and without stroke. IEEE Transactions on Neural Systems and Rehabilitation Engineering: A Publication of the IEEE Engineering in Medicine and Biology Society, 20(6), 778-787. doi:10.1109/TNSRE.2012.2206117

Miller, K. J., Adair, B. S., Pearce, A. J., Said, C. M., Ozanne, E., \& Morris, M. M. (2014). Effectiveness and feasibility of virtual reality and gaming system use at home by older adults for enabling physical activity to improve health-related domains: A systematic review. Age And Ageing, 43(2), 188-195. doi:10.1093/ageing/aft194

Molina, K. I., Ricci, N. A., de Moraes, S. A., \& Perracini, M. R. (2014). Virtual reality using games for improving physical functioning in older adults: A systematic review. Journal of Neuroengineering and Rehabilitation, 11, 156-156. doi:10.1186/1743-0003-11-156

Montero-Alia P, Munoz-Ortiz L, Jimenez-Gonzalez M, et al. Study protocol of a randomized clinical trial evaluating the effectiveness of a primary care intervention using the Nintendo ${ }^{\mathrm{TM}}$ Wii console to improve balance and decrease falls in the elderly. BMC Geriatrics. 2016;16(1). doi:10.1186/s12877-0150178-x

Lin, C. S., Jeng, M. Y., \& Yeh, T. M. (2018). The elderly perceived meanings and values of virtual reality leisure activities: A means-end chain approach. International Journal of Environmental Research and Public Health, 15(4), 663. doi:10.3390/ijerph15040663

Maillot, P., Dommes, A., Dang, N. T., \& Vienne, F. (2017). Training the elderly in pedestrian safety: Transfer effect between two virtual reality simulation devices. Accident Analysis and Prevention, 99, 161-170. doi:10.1016/j.aap.2016.11.017

Manera, V., Chapoulie, E., Bourgeois, J., Guerchouche, R., David, R., Ondrej, J., . . Robert, P. (2016). A feasibility study with image-based rendered virtual reality in patients with mild cognitive impairment and dementia. Plos One, 11(3), e0151487-e0151487. doi:10.1371/journal.pone.0151487

Marcelino, I., Laza, R., Domingues, P., Gómez-Meire, S., Fdez-Riverola, F., \& Pereira, A. (2018). Active and assisted living ecosystem for the elderly. Sensors, 18(4), 1246. doi:10.3390/s18041246

Mattan, B. D., Quinn, K. A., Acaster, S. L., Jennings, R. M., \& Rotshtein, P. (2017). Prioritization of self-relevant perspectives in ageing. Quarterly Journal of Experimental Psychology, 70(6), 1033-1052. doi:10.1080/17470218.2015.1127399 
McDonald, D. D., Walsh, S., Vergara, C., \& Gifford, T. (2013). Effect of a virtual pain coach on pain management discussions: A pilot study. Pain Management Nursing: Official Journal of The American Society of Pain Management Nurses, 14(4), 200-209. doi:10.1016/j.pmn.2011.03.004

Menzies, R. J., Rogers, S. J., Phillips, A. M., Chiarovano, E., de Waele, C., Verstraten, F. A., \& MacDougall, H. (2016). An objective measure for the visual fidelity of virtual reality and the risks of falls in a virtual environment. Virtual Reality, 20(3), 173-181. doi:10.1007/s10055-016-0288-6

Mirelman, A., Rochester, L., Maidan, I., Del Din, S., Alcock, L., Nieuwhof, F., . . Hausdorff, J. M. (2016). Addition of a non-immersive virtual reality component to treadmill training to reduce fall risk in older adults (V-TIME): A randomised controlled trial. Lancet, 388(10050), 1170-1182. doi:10.1016/S0140-6736(16)31325-3

Mirelman, A., Rochester, L., Reelick, M., Nieuwhof, F., Pelosin, E., Abbruzzese, G., . . Hausdorff, J. M. (2013). V-TIME: A treadmill training program augmented by virtual reality to decrease fall risk in older adults: Study design of a randomized controlled trial. BMC Neurology, 13, 15-15. doi:10.1186/14712377-13-15

Mohammadi, A., Kargar, M., \& Hesami, E. (2018). Using virtual reality to distinguish subjects with multiple- but not single-domain amnestic mild cognitive impairment from normal elderly subjects. Psychogeriatrics: The Official Journal of the Japanese Psychogeriatric Society, 18(2), 132-142. doi:10.1111/psyg.12301

Monteiro-Junior, R. S., da Silva Figueiredo, L. F., Maciel-Pinheiro, P. d. T., Abud, E. L. R., Braga, A. E. M. M., Barca, M. L., . . . Laks, J. (2017). Acute effects of exergames on cognitive function of institutionalized older persons: A single-blinded, randomized and controlled pilot study. Aging Clinical and Experimental Research, 29(3), 387-394. doi:10.1007/s40520-016-0595-5

Nir-Hadad, S. Y., Weiss, P. L., Waizman, A., Schwartz, N., \& Kizony, R. (2017). A virtual shopping task for the assessment of executive functions: Validity for people with stroke. Neuropsychological Rehabilitation, 27(5), 808-833. doi:10.1080/09602011.2015.1109523

Ofstedal, M. B., Zimmer, Z. S., \& Lin, H. S. (1999). A comparison of correlates of cognitive functioning in older persons in Taiwan and the United States. The Journals of Gerontology Series B: Psychological Sciences and Social Sciences, 54(5), S291-S301.

Palacio, R. R., Acosta, C. O., Cortez, J., \& Morán, A. L. (2017). Usability perception of different video game devices in elderly users. Universal Access in the Information Society, 16(1), 103-113. doi:10.1007/s10209-015-0435-y

Palacio, R. R., Acosta, C. O., Cortez, J., \& Morán, A. L. (2017). Usability perception of different video game devices in elderly users. Universal Access in the Information Society, 16(1), 103-113. doi:10.1007/s10209-015-0435-y

Palazzo, C., Klinger, E., Dorner, V., Kadri, A., Thierry, O., Boumenir, Y., . . . Ville, I. (2016). Barriers to home-based exercise program adherence with chronic low back pain: Patient expectations regarding new technologies. Annals of Physical and Rehabilitation Medicine, 59(2), 107-113. doi:10.1016/j.rehab.2016.01.009

Park, J., \& Yim, J. (2016). A new approach to improve cognition, muscle strength, and postural balance in community-dwelling elderly with a 3-D virtual reality Kayak program. The Tohoku Journal of Experimental Medicine, 238(1), 1-8. doi:10.1620/tjem.238.1

Paquin, K., Crawley, J., Harris, J. E., \& Horton, S. (2016). Survivors of chronic stroke - participant evaluations of commercial gaming for rehabilitation. Disability and Rehabilitation, 38(21), 2144-2152. doi:10.3109/09638288.2015.1114155

Parijat, P., Lockhart, T. E., \& Liu, J. (2015). Effects of perturbation-based slip training using a virtual reality environment on slip-induced falls. Annals of Biomedical Engineering, 43(4), 958-967. doi:10.1007/s10439-014-1128-z

Park, Y. S., \& Kim, H. J. (2005). Effects of a taping method on pain and ROM of the knee joint in the elderly. Journal of Korean Academy of Nursing, 35(2), 372-381. doi:10.4040/jkan.2005.35.2.372 
Parsons, T. D., \& Barnett, M. (2017). Validity of a newly developed measure of memory: Feasibility study of the virtual environment grocery store. Journal of Alzheimer's Disease: JAD, 59(4), 1227-1235. doi:10.3233/JAD-170295

Pigford, T., \& Andrews, A. W. (2010). Feasibility and benefit of using the Nintendo Wii Fit for balance rehabilitation in an elderly patient experiencing recurrent falls. Journal of Student Physical Therapy Research, 2(1), 12-20.

Plancher, G., Tirard, A., Gyselinck, V., Nicolas, S., \& Piolino, P. (2012). Using virtual reality to characterize episodic memory profiles in amnestic mild cognitive impairment and Alzheimer's disease: Influence of active and passive encoding. Neuropsychologia, 50(5), 592-602. doi:10.1016/j.neuropsychologia.2011.12.013

Rand, D., Weingarden, H., Weiss, R., Yacoby, A., Reif, S., Malka, R., . . Zeilig, G. (2017). Selftraining to improve UE function at the chronic stage post-stroke: A pilot randomized controlled trial. Disability and Rehabilitation, 39(15), 1541-1548. doi:10.1080/09638288.2016.1239766

Rendon, A. A., Lohman, E. B., Thorpe, D., Johnson, E. G., Medina, E., \& Bradley, B. (2012). The effect of virtual reality gaming on dynamic balance in older adults. Age and ageing, 41(4), 549-552. doi:10.1093/ageing/afs053

Riva, G., Bacchetta, M., Baruffi, M., \& Molinari, E. (2001). Virtual reality-based multidimensional therapy for the treatment of body image disturbances in obesity: A controlled study. CyberPsychology \& Behavior, 4(4), 511-526. doi:10.1089/109493101750527079

Rizzo, A. S., \& Kim, G. J. (2005). A SWOT analysis of the field of virtual reality rehabilitation and therapy. Presence: Teleoperators \& Virtual Environments, 14(2), 119-146. doi:10.1162/1054746053967094

Saldana, S. J., Marsh, A. P., Rejeski, W. J., Haberl, J. K., Wu, P., Rosenthal, S., \& Ip, E. H. (2017). Assessing balance through the use of a low-cost head-mounted display in older adults: A pilot study. Clinical Interventions in Aging, 12, 1363-1370. doi:10.2147/CIA.S141251

Skjæret, N., Nawaz, A., Morat, T., Schoene, D., Helbostad, J. L., \& Vereijken, B. (2016). Exercise and rehabilitation delivered through exergames in older adults: An integrative review of technologies, safety and efficacy. International journal of medical informatics, 85(1), 1-16. doi:10.1016/j.ijmedinf.2015.10.008

Sweller, J., Van Merrienboer, J. J., \& Paas, F. G. (1998). Cognitive architecture and instructional design. Educational Psychology Review, 10(3), 251-296. doi:10.1023/A:1022193728205

Talamo, A., Camilli, M., Di Lucchio, L., \& Ventura, S. (2017). Information from the past: how elderly people orchestrate presences, memories and technologies at home. Universal Access in the Information Society, 16(3), 739-753. doi:10.1007/s10209-016-0508-6

Tsang, W. W. N., \& Fu, A. S. N. (2016). Virtual reality exercise to improve balance control in older adults at risk of falling. Hong Kong Medical Journal, 22(1) Suppl 2, S19-S22.

Valladares-Rodriguez, S., Perez-Rodriguez, R., Facal, D., Fernandez-Iglesias, M. J., Anido-Rifon, L., \& Mourino-Garcia, M. (2017). Design process and preliminary psychometric study of a video game to detect cognitive impairment in senior adults. PeerJ, 5, e3508. doi:10.7717/peerj.3508

Vallejo, V., Wyss, P., Rampa, L., Mitache, A. V., Müri, R. M., Mosimann, U. P., \& Nef, T. (2017). Evaluation of a novel Serious Game based assessment tool for patients with Alzheimer's disease. Plos One, 12(5), e0175999. doi:10.1371/journal.pone.0175999

Wollersheim, D., Merkes, M., Shields, N., Liamputtong, P., Wallis, L., Reynolds, F., \& Koh, L. (2010). Physical and psychosocial effects of Wii video game use among older women. International Journal of Emerging Technologies and Society, 8(2), 85-98.

Yardley, L., \& Redfern, M. S. (2001). Psychological factors influencing recovery from balance disorders. Journal of Anxiety Disorders, 15(1-2), 107-119. doi:10.1016/S0887-6185(00)00045-1

Yasuda, K., Muroi, D., Ohira, M., \& Iwata, H. (2017). Validation of an immersive virtual reality system for training near and far space neglect in individuals with stroke: A pilot study. Topics in Stroke Rehabilitation, 24(7), 533-538. doi:10.1080/10749357.2017.1351069 
Yeşilyaprak, S. S., Yıldırım, M. Ş., Tomruk, M., Ertekin, Ö., \& Algun, Z. C. (2016). Comparison of the effects of virtual reality-based balance exercises and conventional exercises on balance and fall risk in older adults living in nursing homes in Turkey. Physiotherapy Theory and Practice, 32(3), 191-201. doi:10.3109/09593985.2015.1138009

Zygouris, S., Giakoumis, D., Votis, K., Doumpoulakis, S., Ntovas, K., Segkouli, S., . . Tsolaki, M. (2015). Can a virtual reality cognitive training application fulfill a dual role? Using the virtual supermarket cognitive training application as a screening tool for mild cognitive impairment. Journal of Alzheimer's Disease: JAD, 44(4), 1333-1347. doi:10.3233/JAD-141260 


\section{KEY TERMS AND DEFINITIONS}

Virtual reality: An interactive computer generate experience within a simulate environment and involves different types of sensory feedbacks.

Exergame: A combination of exercise and gaming, exergame are video games that are also a form of exercise.

Serious game: A game that is designed for a primary purpose other that pure entertainment. The serious adjective refers to issues such as defense, education, health care, engineering, and politics. Alzheimer's disease: Is a neurodegenerative disease that involves short-term memory loss, language disorientation, and other behavioral issues.

Mild cognitive impairment: Is a neurological disorder that happens in older adults and involves cognitive and instrumental activities of daily living impairments.

Ecological validity: Refers to the extent to which the results of a research could be generalized to the real life settings.

Skill transfer: Is the concept of exploring how individuals would transfer learning in one context to another one. 